\title{
ARTICLE OPEN Remote effect of a tropical cyclone in the Bay of Bengal on a heavy-rainfall event in subtropical East Asia
}

\author{
Sho Arakane (D) ${ }^{1}$, Huang-Hsiung Hsu (D) ${ }^{1}$, Chia-Ying Tu (D)', Hsin-Chien Liang (D) ${ }^{1}$, Zheng-Yu Yan (D) ${ }^{1}$ and Shian-Jiann Lin ${ }^{2}$
}

Torrential frontal rainfall occurred over Northern Taiwan on June 2, 2017. Prior to this rainfall, tropical cyclone (TC) Mora formed in the Bay of Bengal. This study investigated the triggering effect of TC Mora on the heavy-rainfall system through numerical experiments. The numerical experiments, in which TC Mora was included or excluded in the initial conditions, revealed that TC Mora strengthened the southwesterly winds, which effectively transported tropical warm moist air toward Taiwan, and the cool dry northerly winds to the north of Taiwan. The strengthened southeasterly and northerly winds created a strong frontal system near Taiwan. TC Mora contributed to the heavy frontal rainfall by enhancing tropical-extratropical interaction and vertical coupling in East Asia.

npj Climate and Atmospheric Science (2019)2:25; https://doi.org/10.1038/s41612-019-0082-8

\section{INTRODUCTION}

Taiwan, an island off the east coast of Asia, receives a large amount of precipitation (climatological annual rainfall 2000-3000 mm). Steep topography, the East Asian monsoonal flow, fronts, and tropical cyclones (TCs) are the causes of rainfall in Taiwan. Taiwan experiences five rainy seasons: winter, spring, Mei$Y u$, typhoon, and fall. ${ }^{1}$ The Mei-Yu season (May-June) in Taiwan, the focus of this study, is equivalent to the pre-flooding period in China. Mesoscale convective systems (MCSs) embedded in the $M e i-Y u$ front are the major source of rainfall in the Mei-Yu season. ${ }^{2,3}$ The $M e i-Y u$ front generally possesses a large gradient of equivalent potential temperature, which is associated with a convergence of cool dry air from the north and warm moist air from the southwest. ${ }^{1,4}$ In Northern Taiwan, extreme heavy-rainfall events of as much as $600 \mathrm{~mm}$ of daily rain often occur, when a MCS is supported by a strong low-level jet forming in the northern South China Sea (SCS). ${ }^{5-7}$ The low-level jet over SCS that transports warm moist air toward Taiwan effectively is named as the marine boundary layer jet (MBLJ) in a recent study. ${ }^{8}$

On June 2, 2017, torrential rainfall occurred in Northern Taiwan and continued throughout the next day. The Central Weather Bureau in Taiwan reported that during the event, 2- and 12-h rainfall amounts in Northern Taiwan exceed 120 and $600 \mathrm{~mm}$, respectively. This heavy rainfall induced flooding and landslides. Two people were killed, and three people were reported missing during this incident. The CWB reported that a Mei-Yu front associated with southwesterly winds induced the heavy-rainfall event. The observed heavy rainfall (exceeding $600 \mathrm{~mm}$ in $12 \mathrm{~h}$ ) in this event was record breaking for the events associated with a Mei-Yu front during recent 26 years. ${ }^{9}$

Prior to the heavy rainfall, TC Mora formed in the Bay of Bengal (BOB) on May 28, 2017 and dissipated on May 31, 2017. Himawari8 satellite images demonstrated the deep convection of TC Mora and the upper-level thin cloud accompanying the outflow to the north of TC Mora on May 30, 2017 (see Supplementary Movie 1). TC Mora dissipated at 0000 UTC on May 31, 2017, but the thin cloud remained in the region to the northeast of the BOB. In the next few days, the thin cloud moved east over the East China Sea, and a frontal system was observed to the northwest of Taiwan. The frontal system shifted southeastward toward Taiwan on June 2, 2017 and induced heavy rainfall on the island (details of southeastward movement of the frontal system will be discussed later). In addition, the southwesterly winds prevailing from the BOB to the northern SCS were enhanced following TC Mora. In view of the association of the aforementioned upper tropospheric perturbation and low-level southwesterly winds with TC Mora, the frontal development was hypothesized to be associated with TC Mora. A systematic study was required to investigate whether and how TC Mora contributed to the heavy rainfall.

Did TC Mora help trigger or enhance the heavy rainfall? To answer this question, we assessed the effect of TC Mora on the heavy rainfall by conducting two sets of hindcast experiments, one with TC Mora included in the initial condition and one with TC Mora artificially removed from the initial condition. We will present the detailed descriptions of the numerical model, observational data, and analysis method used in this study in the "Methods" section.

\section{RESULTS}

Observation

Figure 1 shows the satellite-based rainfall with low-level horizontal wind and a wind shift line (WSL). Following the previous study, ${ }^{10}$ the WSL was defined as a boundary where the horizontal wind direction is abruptly changed. Because it was difficult to detect the leading edge of the "frontal zone" using thermal variables in this case, we used the WSL to show the approximate location of air masses' boundary (i.e., the leading edge of a baroclinic zone) near Taiwan. The WSL was located in Eastern China at 0000 UTC on June 1, 2017 (Fig. 1c) and moving southeastward. Accompanied with the movement of the WSL, the well-organized frontal rainfall system shifted to the southeast with time. As shown in Fig. 1, the

\footnotetext{
${ }^{1}$ Research Center for Environmental Changes, Academia Sinica, Taipei, Taiwan and ${ }^{2}$ NOAA/Geophysical Fluid Dynamics Laboratory, Princeton, NJ, USA Correspondence: Huang-Hsiung Hsu (hhhsu@gate.sinica.edu.tw)
}

Received: 13 February 2019 Accepted: 2 July 2019

Published online: 24 July 2019 

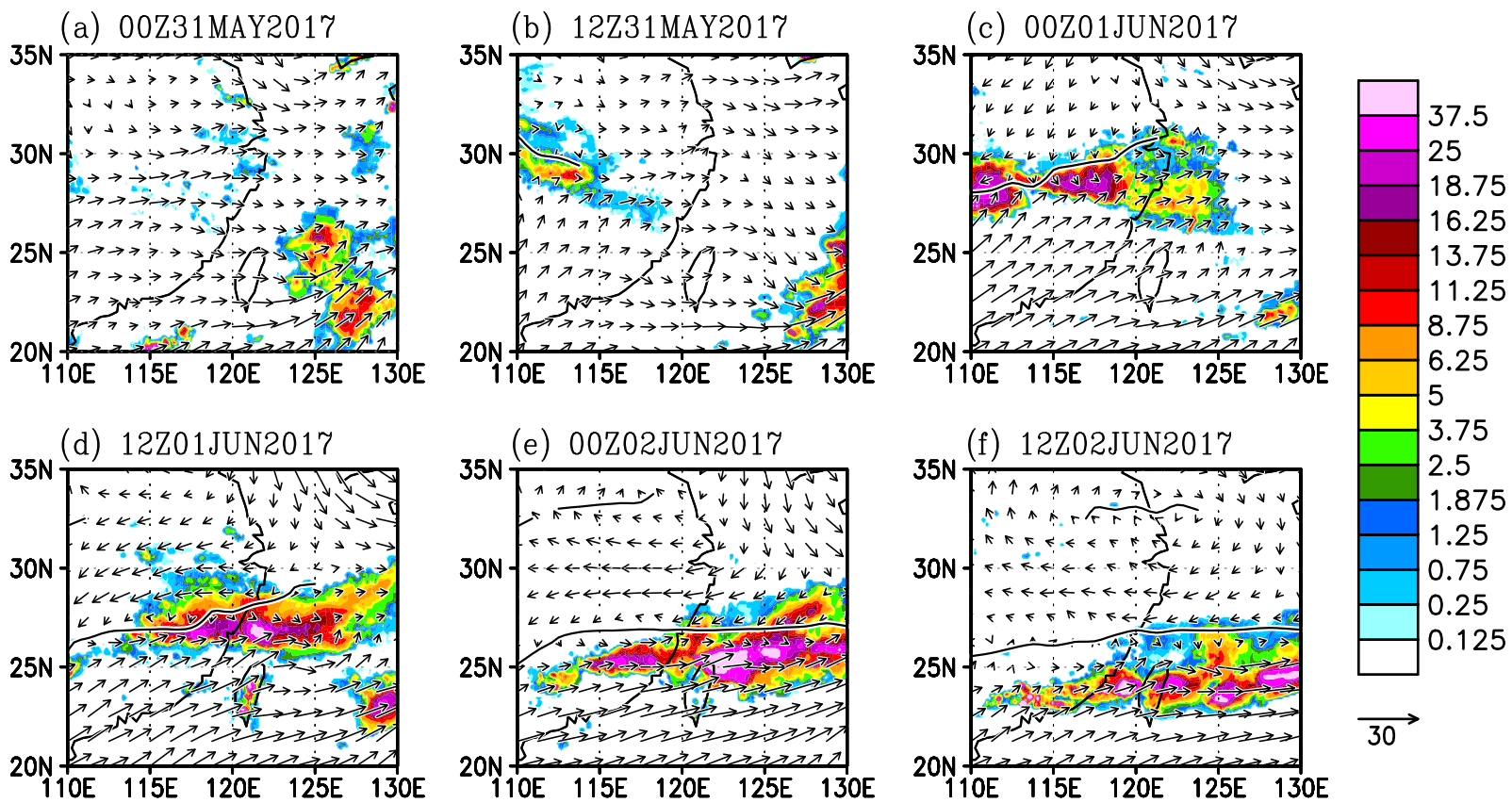

Fig. 1 Three-hourly accumulated rainfall $\left[\mathrm{mm}(3 \mathrm{~h})^{-1}\right.$ ] obtained from the GSMaP_MVK. The start time for the 3-hourly rainfall accumulation is a 0000 UTC, b 1200 UTC on May 31, c 0000 UTC, d 1200 UTC on June 1, e 0000 UTC, and f 1200 UTC on June 2, 2017. Vectors represent 850-hPa horizontal wind and the solid lines show the wind shift lines obtained from the JRA-55 at the start time for precipitation accumulation

heavy rainfall over Northern Taiwan started between 1200 UTC on June 1 and 0000 UTC on June 2, 2017.

Next, we analyzed the synopsis of the heavy-rainfall system after the onset of heavy rainfall over Northern Taiwan (at 1800 UTC on June 1, 2017). The upper-level northerly wind component and subsidence were observed to the north of Taiwan $\left(\sim 40^{\circ} \mathrm{N}\right.$, $125^{\circ} \mathrm{E}$ ) along the western periphery of an upper trough (Fig. 2a). Furthermore, the subsiding northerly winds were observed to the north of the WSL in the cross section along $121^{\circ} \mathrm{E}$ (Fig. 2f). Thus, the low-level northerly winds situated to the north of Taiwan shown in Fig. 1, were vertically linked with the upper-level system. On the other hand, the low-level southwesterly winds toward Taiwan transported moisture-laden air to Taiwan. As a result, the low-level southwesterly and northerly winds created a large moisture flux convergence near Taiwan (Fig. 2b). The vertical cross section from $25^{\circ} \mathrm{N}, 117.5^{\circ} \mathrm{E}$ to $20^{\circ} \mathrm{N}$, and $120^{\circ} \mathrm{E}$ shown in Fig. $2 \mathrm{C}$ reveals that the strong low-level southwesterly winds (i.e., a MBLJ) were confined below $850 \mathrm{hPa}$ as in many case studies of the Mei$\mathrm{Yu}$ fronts. Compared with a climatology of MBLJ using the National Centers for Environmental Prediction (NCEP) Climate Forecast System Reanalysis (CFSR) data from 2008 to 2012 during May-June with 6 -hourly $0.5^{\circ}$ latitude-longitude grids, ${ }^{8}$ the maximum speed of MBLJ in this case is 50\% larger than its 5year climatology ( 19 vs. $12.5 \mathrm{~m} \mathrm{~s}^{-1}$ ). Note that the horizontal resolution of JRA-55 used here is coarser than CFSR data $\left(1.25^{\circ}\right.$ vs. $0.5^{\circ}$ ). A higher-resolution data might yield an even stronger MBLJ.

Finally, we investigated the frontal development induced by the horizontal confluent flow. Along the WSL, both the divergence and deformation terms of the frontogenetical function $\left(F_{\text {div }}\right.$ and $F_{\text {def, }}$ respectively), which were the dominant terms in the budget equation, were positive at low level (Fig. $2 \mathrm{~d}$, e). This means that low-level convergence and deformation induced by the northerly winds to the north of Taiwan and the MBLJ to the southwest of Taiwan positively contributed to the frontal development. The north-south vertical cross section of $F_{\text {def }}$ also shows the positive contribution of deformation term to the frontal development in the south of the WSL that tilted northward with height (Fig. 2f). A noteworthy feature is the distinguished upward motion over the positive $F_{\text {def }}$ near the surface where large precipitation occurred near the front.

\section{Numerical experiments}

In this subsection, we reveal the contribution of TC Mora to the frontal rainfall system by contrasting the control experiment and sensitivity experiment in which TC Mora is removed (for more details, see the "Methods" section) using the fvGFS. The simulated 3-h accumulated precipitation is shown in Fig. 3. In the control experiment, although the $13-\mathrm{km}$ spatial resolution used for the experiments was not sufficiently high to resolve the steep topography in Taiwan, the characteristics of the heavy-rainfall system over Northern Taiwan were realistically reproduced: a wellorganized rainfall system with an amount comparable with that observed (Fig. 3a-c). Furthermore, as revealed in the JRA-55, the rainfall system shifted to the southeast along with the southeastward movement of the simulated WSL (black-colored solid lines). By contrast, the rainfall system simulated in the sensitivity experiment was less organized with smaller amount of rainfall (Fig. $3 \mathrm{~d}$, e). A heavy rainfall over Northern Taiwan was simulated after $12 \mathrm{~h}$, but the west-east elongated rainband structure, which was well simulated in the control experiment, was not as well organized (Figs $2 f$ and $3 c$, f). Moreover, the WSL in the sensitivity experiment always stayed to the north of the one simulated in the control experiment (red-colored solid lines). This suggests that the boundary of air masses to the north of Taiwan shifted further southward because of the further equatorward penetration of northerly winds under the influence of TC Mora.

The existence of TC Mora modulated other dynamic fields over East Asia as well. Figure $4 \mathrm{a}, \mathrm{b}$ shows the simulated upper-level fields. As revealed in the JRA-55, subsiding northerly winds component along the western periphery of upper trough to the north of Taiwan was well simulated in the control experiment (Fig. 4a). By contrast, the location and strength of upper trough and vertical motion simulated in the sensitivity experiment were much less realistic (Fig. 4b). This can be seen clearly in the differences between two experiments. As shown in Fig. 4c, a wave-like pattern was seen centered around the Korean Peninsula in the difference 
(a) $\omega, \mathrm{Z}, 300 \mathrm{hPa}$

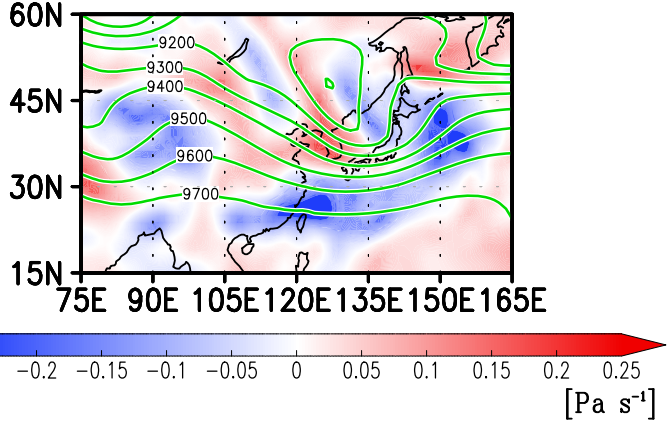

(b) $\nabla \cdot(\mathrm{qV}), \mathrm{u}, \mathrm{v}, 925 \mathrm{hPa}$

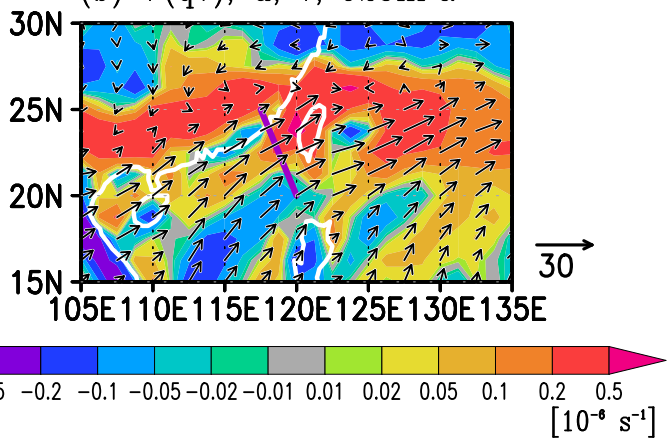

(c) LLJ, $(25 \mathrm{~N}, 117.5 \mathrm{E})-(20 \mathrm{~N}, 120 \mathrm{E})$

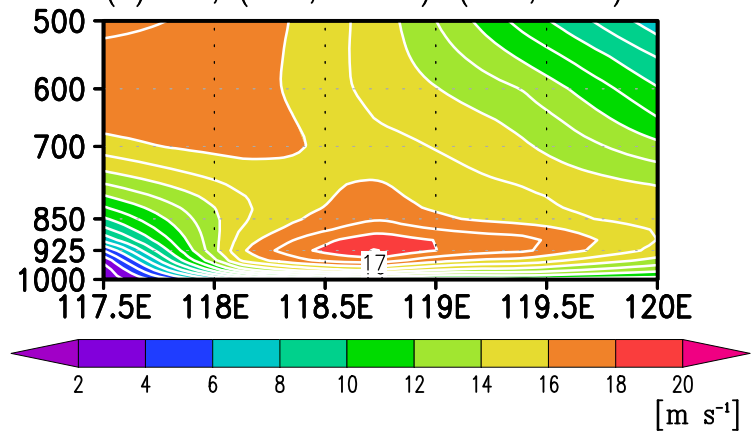

(d) Frontogenesis, Div., $850 \mathrm{hPa}$
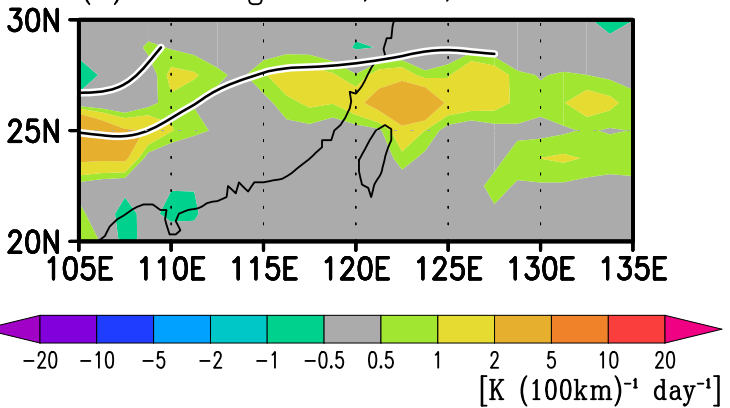

(e) Frontogenesis, Def., $850 \mathrm{hPa}$
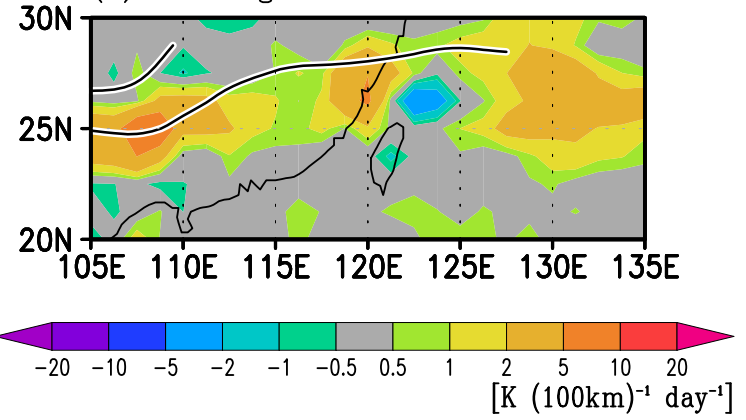

(f) Frontogenesis, Def., CS (121E)

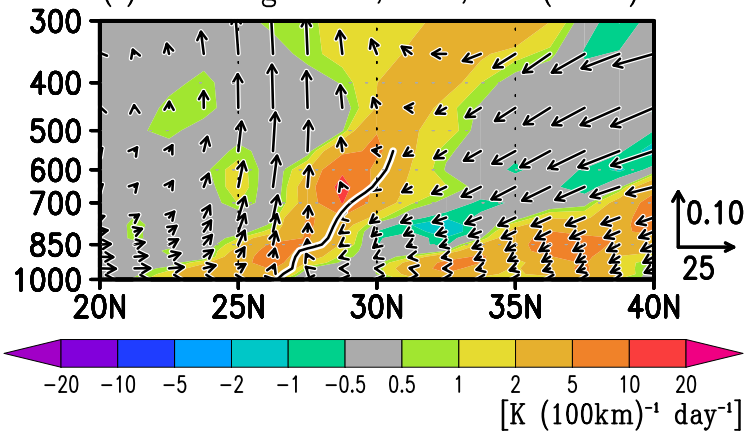

Fig. 2 Synopsis of the heavy rainfall obtained from the JRA-55 at 1800 UTC on June 1, 2017. a Daily-averaged vertical pressure velocity (color, $\mathrm{Pa} \mathrm{s}^{-1}$ ) and daily-averaged geopotential height (contour, gpm) at $300 \mathrm{hPa}$. b Daily-averaged moisture (specific humidity) flux convergence (color, $\mathrm{s}^{-1}$ ) and daily-averaged horizontal wind (vector, $\mathrm{m} \mathrm{s}^{-1}$ ) at $925 \mathrm{hPa}$. c Vertical cross section of daily-averaged horizontal wind component perpendicular to the section (color and contour, contour interval is $1 \mathrm{~m} \mathrm{~s}^{-1}$ ). Location of the cross section is indicated as the purple-colored solid line in b. d Daily-averaged divergent term in the frontogenetical function equation [color, $\mathrm{K}(100 \mathrm{~km})^{-1}$ day ${ }^{-1}$ ] at $850 \mathrm{hPa}$. The solid line represents the wind shift line at $850 \mathrm{hPa}$. e Same as $\mathbf{d}$ but for the deformation term. $\mathbf{f}$ Vertical cross section of daily-averaged the deformation term in the frontogenetical function equation [color, $\mathrm{K}(100 \mathrm{~km})^{-1}$ day $^{-1}$ ] and daily-averaged transverse circulation (vector, $\left.\mathrm{m} \mathrm{s}^{-1}\right)$ along $121^{\circ} \mathrm{E}$ (the plotted data are zonally averaged between $119^{\circ}$ and $123^{\circ} \mathrm{E}$ ). The solid line represents the wind shift line

between the control and sensitivity experiments. This difference reflected the better skill of the control experiment in hindcasting the extratropical perturbation crossing East China, Korea, and Japan that helped set up an environment favorable for the development of the frontal system. As a result, the enhancement of northerly winds and subsidence over the Yellow Sea $\left(\sim 35^{\circ} \mathrm{N}\right.$, $\left.123^{\circ} \mathrm{E}\right)$ were more realistically simulated in the control experiment. This means that the existence of TC Mora enhanced the subsiding northerly winds to the north of Taiwan by modulating the upper-level circulation. Note that this subsiding northerly winds prevailed through the entire troposphere as seen in Fig. $2 \mathrm{f}$. Therefore, the existence of the upper trough played an important role in inducing the northerly winds. This effect was much better hindcast in the control experiment. To confirm how TC Mora modulated the upper-level circulation, we investigated temporal evolution of differences in the upper-level streamfunction and wave activity flux (WAF) ${ }^{11}$ between the control and sensitivity experiments. The streamfunction differences clearly indicated the development of a wave-like structure emanating northeastward from the tip of the $B O B$, as indicated by the WAF similar to the Rossby wave dispersion triggered by a heat source (Fig. $4 \mathrm{~d}-\mathrm{f}$ or Supplementary Fig. 2 in a larger domain). This contrast between two experiments suggests that TC Mora modulated the upperlevel structure over East Asia through the processes of northeastward wave energy propagation, and the modulated upperlevel field enhanced the northerly winds and subsidence to the north of Taiwan and the associated frontogenesis.

In addition to enhancing the upper-level fields, TC Mora modulated the low-level fields around Taiwan to favor the development of the frontal system. The observed low-level southwesterly winds toward Taiwan, large moisture flux convergence, and MBLJ were reproduced in both experiments 

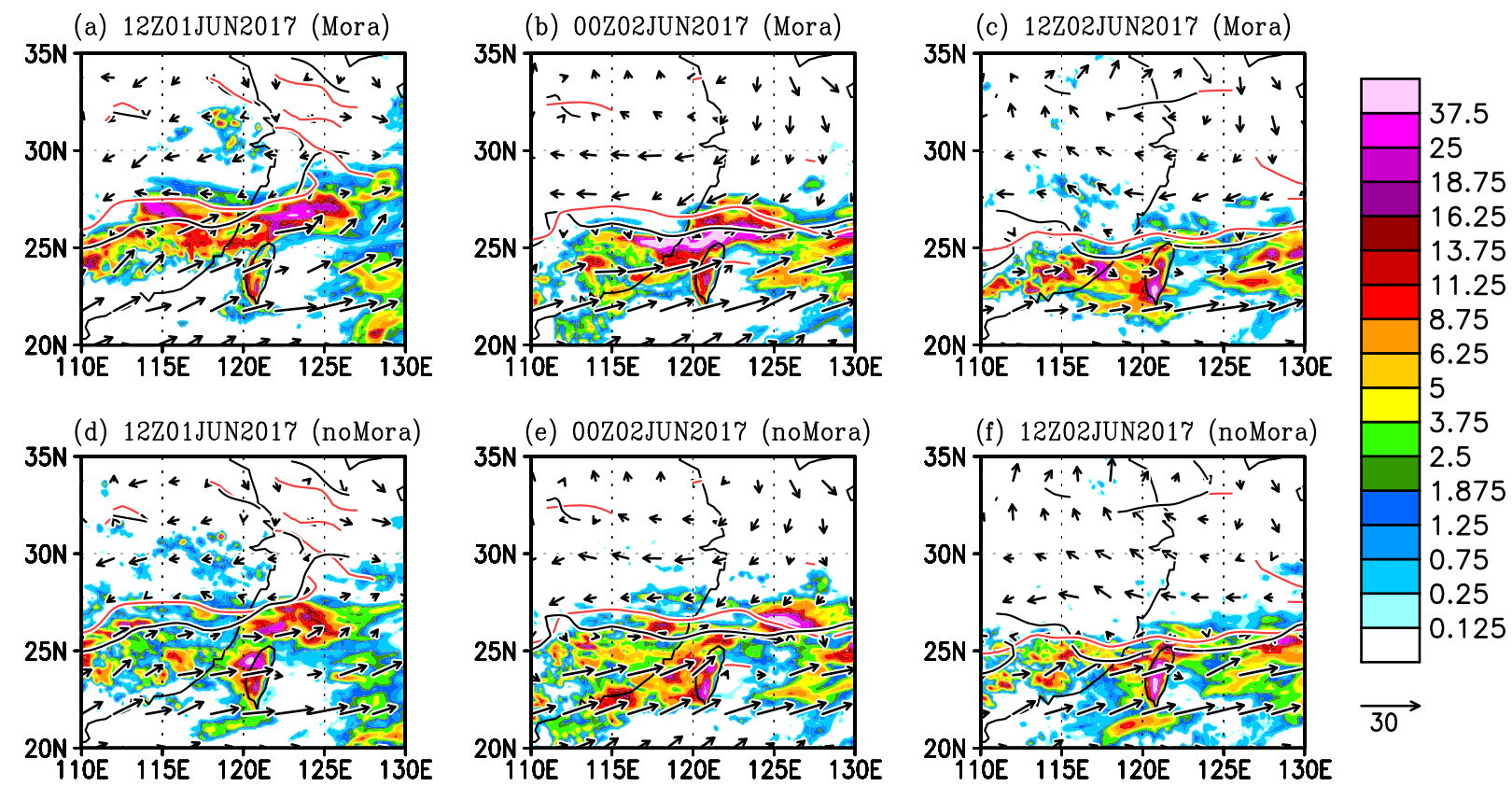

Fig. 3 (Top) Three-hourly accumulated rainfall $\left[\mathrm{mm}(3 \mathrm{~h})^{-1}\right.$ ] obtained from the control experiment. The start time for the 3-hourly rainfall accumulation is a 1200 UTC on June 1, b 0000 UTC, and c 1200 UTC on June 2, 2017. (Bottom) The same as the top panel but for the results in the sensitivity experiment. The black- and red-colored solid lines show the wind shift lines in the control and sensitivity experiments, respectively

(Fig. 4g-k). However, Fig. 4j-I shows that the MBLJ in the control experiment was notably stronger and wider than in the sensitivity experiment (e.g., the maximum speed of MBLJs were $\sim 19.8 \mathrm{~m} \mathrm{~s}^{-1}$ and $17.7 \mathrm{~m} \mathrm{~s}^{-1}$ ), especially in the area closer to Taiwan (i.e., $119^{\circ}$ $\left.\mathrm{E}-120^{\circ} \mathrm{E}\right)$. The moisture flux convergence around Taiwan was therefore much stronger in the control experiment (Fig. 4i). It follows that the existence of TC Mora enhanced the MBLJ, which transported large amount of low-level moisture toward Taiwan, and created a considerably favorable condition for the heavy rainfall in Northern Taiwan.

Although TC Mora changed the location of the front through modulating the dynamic field over East Asia, how TC Mora contributed to the frontal intensity needed to be evaluated. The low-level positive contributions by $F_{\text {div }}$ and $F_{\text {def }}$ on the frontal development near Taiwan were well reproduced in the control experiment as in the JRA-55 analysis (Fig. 5a, C). Larger positive contribution near Northern Taiwan $\left(\sim 25^{\circ} \mathrm{N}, 121^{\circ} \mathrm{E}\right)$ was simulated in the control experiment, consistent with the better-positioned WSL, as reflected in the differences between experiments shown in Fig. 5b, d. Moreover, the north-south vertical cross section of $F_{\text {def }}$ also shows a result more consistent with the JRA-55 analysis (Fig. 5e, g): larger positive contribution for the frontal development along the WSL, stronger northerly winds originated in upper level to the north of WSL, stronger southerly winds of tropical origin to the south of WSL, and stronger upward motion over the WSL (Fig. 5f, h). Notably, Fig. $5 f$ shows that the MBLJ and the subsiding northerly winds toward Taiwan were enhanced in the control experiment. Furthermore, although the positions of air masses' boundaries at middle level in the both experiments were almost identical at 1800 UTC on June 1, 2017, the position notably became different $6 \mathrm{~h}$ later (Fig. $5 \mathrm{~g}, \mathrm{~h}$ ). Both WSLs had tilted structures from low level to middle level; however, the stronger northerly winds in the control experiment nudged the WSL further south. This implies that the enhancement of the dry northerly and moist southerly winds induced by TC Mora did have large impact on the frontal system. As a result, the enhanced confluence induced by TC Mora not only shifted the location of baroclinic zone but also created the stronger baroclinicity and moisture convergence near Taiwan.

\section{DISCUSSION}

This study demonstrated how TC Mora in the BOB led to the torrential rainfall event over Northern Taiwan on June 2, 2017. This event resulted from the modification of upper-level large-scale and low-level synoptic-scale circulation (namely, the Mei-Yu front). The fvGFS that realistically simulated the torrential rainfall event starting 4 days in advance was used to conduct two hindcast experiments: a control experiment with TC Mora embedded in the initial condition and a sensitivity experiment initialized with TC Mora removed. By analyzing the contrasting results of the two experiments, we identified the physical processes induced by TC Mora that led to the torrential rainfall event. The mechanisms are described as follows:

(1) TC Mora remotely and extensively affected circulation over East Asia.

(2) The effect on circulation enhanced the southwesterly winds over the SCS to the southwest of Taiwan and the northerly winds to the north of Taiwan.

(3) The strengthened and widened MBLJ over the SCS transported moisture-laden air toward Taiwan and enhanced low-level moisture convergence near Taiwan.

(4) The strong northerly winds moved cooler air mass farther southward in the north of Taiwan and promoted the enhancement of low-level convergence.

(5) The stronger confluent zone induced by the strengthening of the warm moist southerly and cool dry northerly winds resulted in a strong baroclinic zone (front), which shifted further southward toward northern Taiwan through the deformation and divergence processes.

(6) The enhanced low-level moisture convergence and frontal system generated heavy rainfall over Northern Taiwan.

One may suspect that the event reported here is similar to a predecessor rain event (PRE). In a PRE, low-level moisture-rich 
(a) $\omega 300$, Z300 (Mora, 18Z01JUN2017)

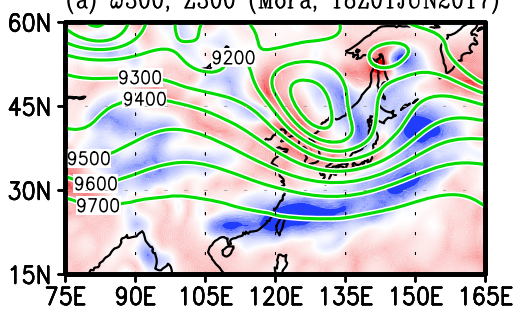

(b) $\omega 300$, Z300 (noMora, 18Z01JUN2017)

(c) $\omega 300$, Z300 (Diff., 18Z01JUN2017)
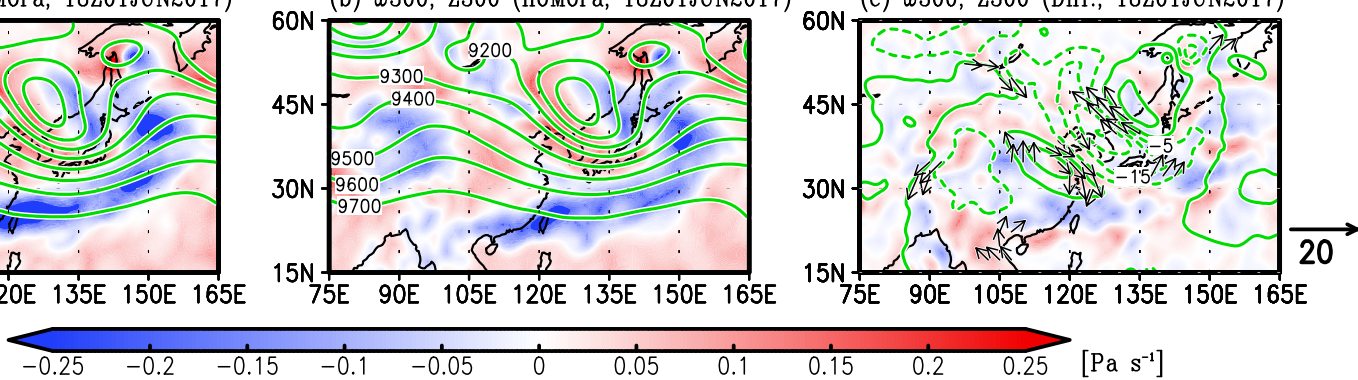

(d) 4300, WAF (Diff., 12Z30MAY2017)

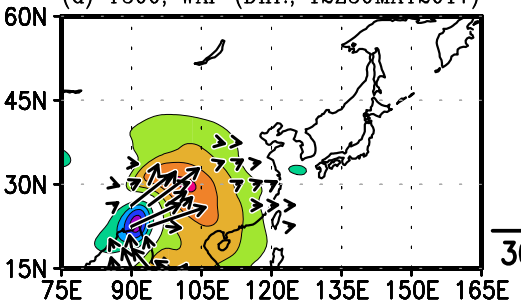

(e) $\Psi 300$, WAF (Diff., 12Z31MAY2017)
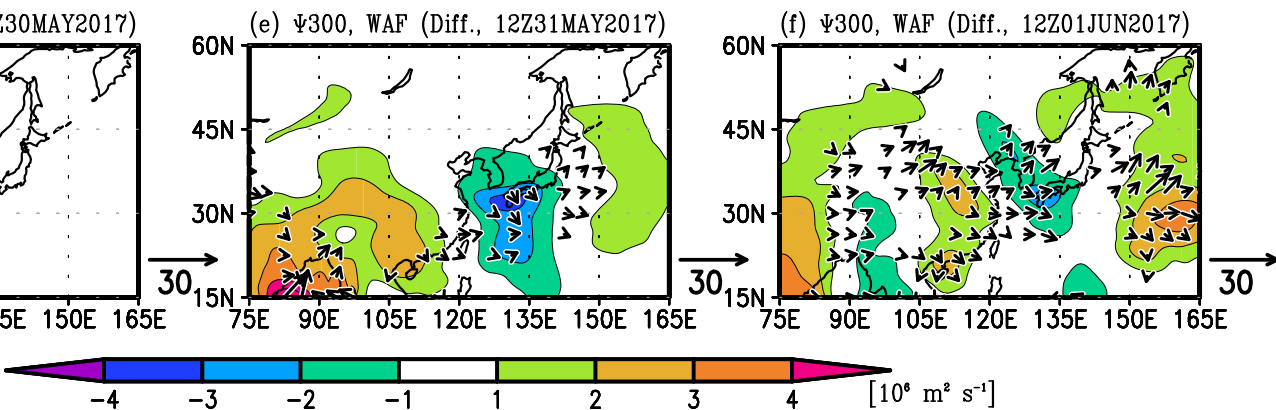

(g) $\nabla \cdot(\mathrm{qV}),($ Mora, $925 \mathrm{hPa})$

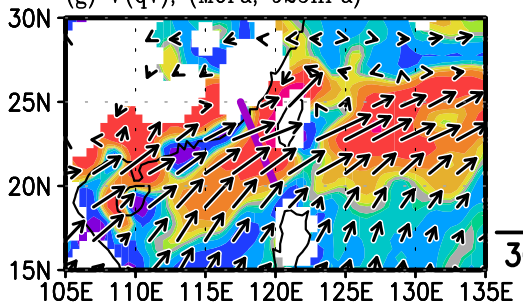

(h) $\nabla \cdot(\mathrm{qV}),($ noMora, $925 \mathrm{hPa})$

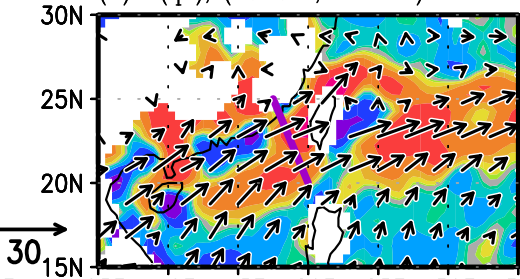

(i) $\nabla \cdot(q V),($ Diff., $925 \mathrm{hPa})$

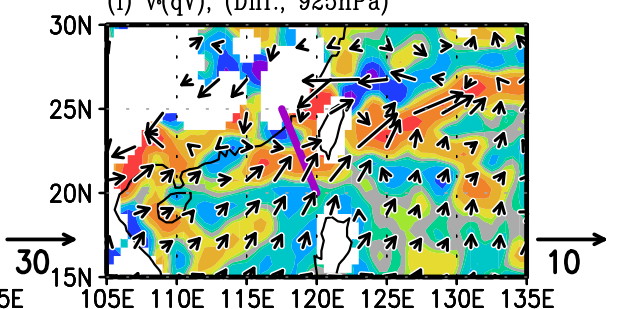

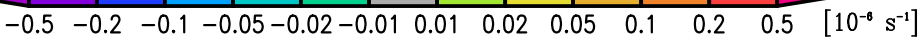

(j) LLJ, (25N,117.5E)-(20N,120E) (Mora)

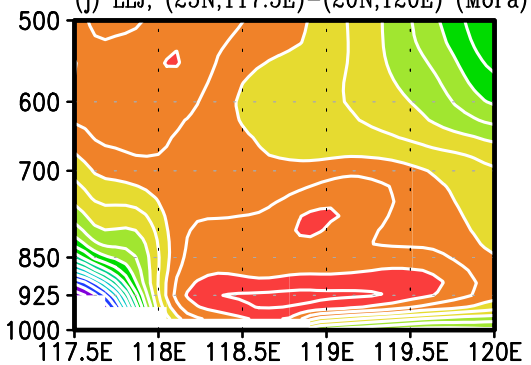

(k) LLJ, $(25 \mathrm{~N}, 117.5 \mathrm{E})-(20 \mathrm{~N}, 120 \mathrm{E})$ (noMora)

(l) LLJ, (25N,117.5E)-(20N,120E) (Diff.)
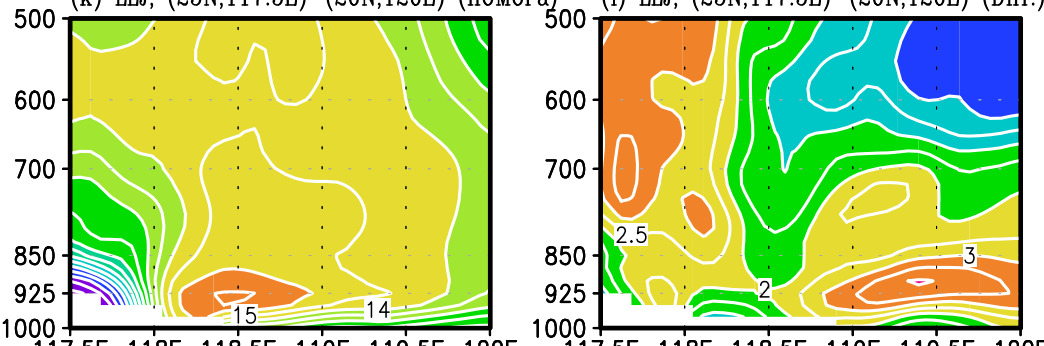

1000

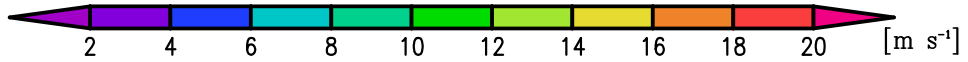

17.5E $118 \mathrm{E} \quad 118.5 \mathrm{E} \quad 119 \mathrm{E}$ 119.5E $120 \mathrm{E}$

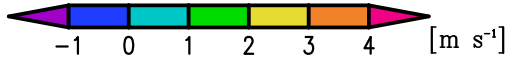

Fig. 4 a, b Daily-averaged 300-hPa vertical pressure velocity (color, Pa s ${ }^{-1}$ ) and daily-averaged geopotential height (contour, gpm) at 1800 UTC on June 1, 2017 in the a control and b sensitivity experiments. c Same as a but for the difference between the control and sensitivity experiments (contour interval is $10 \mathrm{gpm}$ ). Daily-averaged $300-\mathrm{hPa}$ horizontal wind difference is also shown (the wind vector is omitted where its magnitude is smaller than $5 \mathrm{~m} \mathrm{~s}^{-1}$ ). d Difference of streamfunction between the control and sensitivity experiments (color, $\mathrm{m}^{2} \mathrm{~s}^{-1}$ ) and difference of the wave activity fluxes between the control and sensitivity experiments (vector: the vector is omitted where its magnitude is smaller than $2 \mathrm{~m}^{2} \mathrm{~s}^{-2}$ ) at $300 \mathrm{hPa}$ at 1200 UTC on May 30, 2017. e, f Same as d but on May 31 and June 1, respectively. $\mathbf{g}$, $\mathbf{h}$ Daily-averaged $925-$

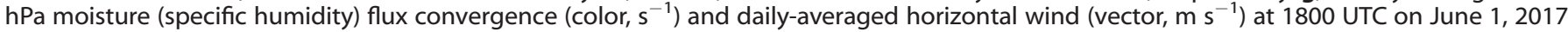
in the $\mathbf{g}$ control and $\mathbf{h}$ sensitivity experiments. $\mathbf{i}$ Same as $\mathbf{g}$ but for the difference between the control and sensitivity experiments. $\mathbf{j}$, $\mathbf{k}$ Vertical cross section of daily-averaged horizontal wind component perpendicular to the section (color and contour, contour interval is $1 \mathrm{~m} \mathrm{~s}^{-1}$ ) in the $\mathbf{j}$ control and $\mathbf{k}$ sensitivity experiments. Location of the cross section is indicated as the purple-colored solid line in $\mathbf{g}$. I Same as $\mathbf{j}$ but for the difference between the control and sensitivity experiments

tropical air is transported by a TC's outer (synoptic-scale) circulation to a frontal zone located in the north and triggers heavy rainfall in the frontal zone. ${ }^{12}$ At the first look, the June 2, 2017 event seemingly exhibited some similarities. However, different characteristics were observed in this event. First, the distances between the TC and frontal zone in PREs are $410-1700 \mathrm{~km},{ }^{12}$ whereas the distance between TC Mora in the $\mathrm{BOB}$ and the frontal zone to the north of Taiwan in the western 

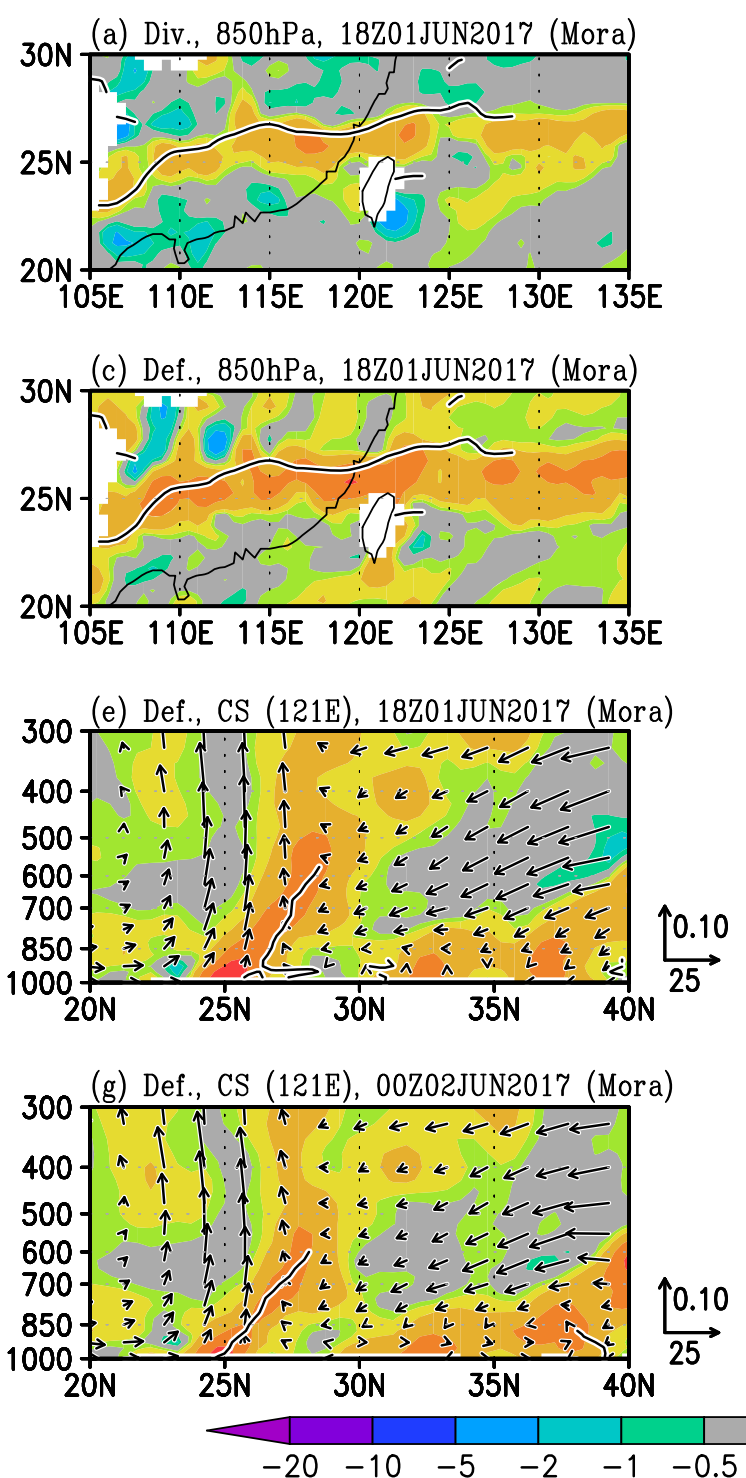

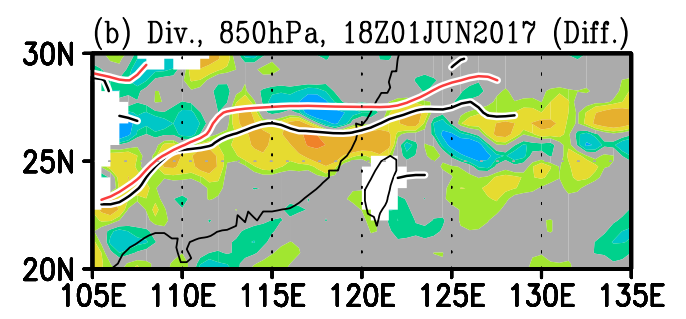

(d) Def., 850hPa, 18Z01JUN2017 (Diff.)
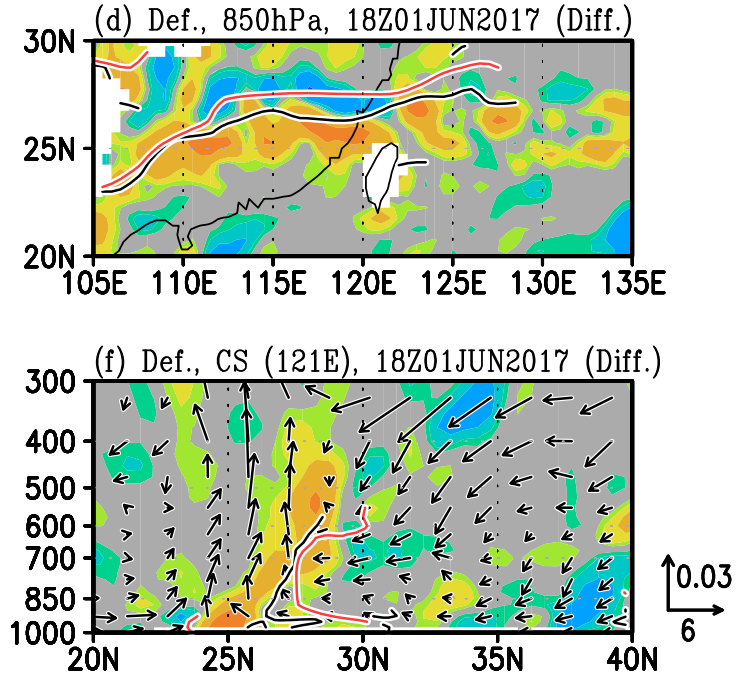

(h) Def., CS (121E), 00Z02JUN2017 (Diff.)

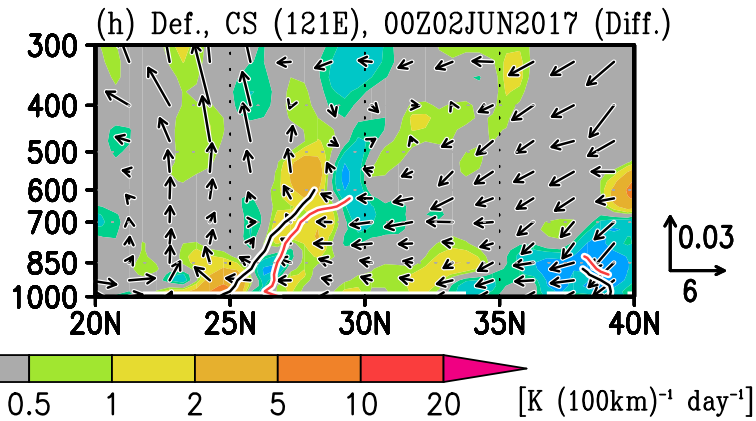

Fig. 5 a Daily-averaged 850 -hPa divergent term in the frontogenetical function equation at 1800 UTC on June 1, 2017 [color, $\mathrm{K}(100 \mathrm{~km})^{-1}$ day ${ }^{-1}$ ]. b Same as a but for the difference between the control and sensitivity experiments. c Same as a but for the deformation term. $\mathbf{d}$ Same as $\mathbf{c}$ but for difference between the control and sensitivity experiments. e Vertical cross section of daily-averaged the deformation term in the frontogenetical function equation [color, $\mathrm{K}(100 \mathrm{~km})^{-1}$ day $^{-1}$ ] and daily-averaged transverse circulation $\left(\right.$ vector, $\left.\mathrm{m} \mathrm{s}^{-1}\right)$ along $121^{\circ} \mathrm{E}$ at 1800 UTC on June 1, 2017 (the plotted data are zonally averaged between 119 and $123^{\circ} \mathrm{E}$ ). f Same as e but for difference between the control and sensitivity experiments. $\mathbf{g}$, $\mathbf{h}$ Same as e, $\mathbf{f}$ but at 0000 UTC on June 2, 2017. The black-colored and red-colored solid lines denote the wind shift lines in the control and sensitivity experiments, respectively

North Pacific was $\sim 3500 \mathrm{~km}$. Thus, the direct contribution of TC outflow to the heavy rain event was extremely low. Remarkably, numerical experiments reveal that TC Mora modified the evolution of the large-scale monsoon circulation and frontal systems, for example, by enhancing the overall low-level cyclonic circulation and emanating a wave-like structure that modified the upper-level circulation over East Asia. The former increased the moisture transport from the SCS, and the latter induced strong cyclonic circulation in the north along with the southward penetration of cool dry air. These modifications suggest that TC Mora remotely enhanced the vertical coupling and the tropical-extratropical interaction in East Asia and led to the extreme heavy rainfall event in Northern Taiwan on June 2, 2017. In addition, the quantitatively similar contribution by TC Mora on the heavy rainfall was identified in all ensemble simulations and ensemble means (Supplementary Figs 2-7). The consistent result strongly supports our finding about the remote impact of TC Mora in the BOB on a frontal system and heavy rainfall event in subtropical East Asia.

To the best of our knowledge, this study is likely the first report on such a remote impact of a TC on the frontal system in East Asia. Our study suggests that a proper representation and forecast of TC Mora, and its remote impact on a model, are necessary for well forecasting the June 2 heavy-rainfall event, especially the timing and location. This implies that a frontal development might not be a pure local event and the consideration of potential effect of a remote disturbance might be needed.

Finally, TC Mora's intensity is weaker than the Category 1 TC in the Saffir-Simpson scale, meaning that TC Mora was not a strong TC. Interestingly, it is shown that a weak TC over the BOB such as TC Mora can influence the weather in East Asia. This suggests that the strength was likely not the major factor leading to the observed impact, meaning that timing and favorable environment provided by the large-scale circulation could be important. In 
addition, whether the remote effect of a TC in the BOB on the heavy rainfall in East Asia is a common process remains to be seen. If not, under what circumstances this remote effect is more likely to occur. A full survey is being planned to answer these questions.

\section{METHODS}

Numerical simulation

We used the Geophysical Fluid Dynamics Laboratory (GFDL) finite-volume dynamical core ${ }^{13-15}$ with the Global Forecast System (GFS) produced by NCEP (fvGFS, a global numerical weather prediction model). ${ }^{16}$ As the radiation scheme, we used the Rapid Radiative Transfer Model for general circulation models. ${ }^{17}$ The cumulus parameterization was the simplified Arakawa-Schubert scheme. ${ }^{18,19}$ The microphysics scheme applied in this study was the six-class single-moment scheme developed by the GFDL. ${ }^{20,21}$ We conducted the simulation with $\sim 13-\mathrm{km}$ horizontal resolution globally and 64 vertical levels with a model top at $\sim 0.3 \mathrm{hPa}$. Using the NCEP-GFS analysis data, we initialized the experiment at 0000 UTC on May 29,2017 , and integrated for 7 days. Although the horizontal resolution of the NCEP-GFS analysis data is coarser than of the fvGFS simulation, the "initial shock" of convection in the simulation was suppressed within a day. The experiment captured the mature phase and dissipation of TC Mora in the BOB and the strong frontal rainfall system over Northern Taiwan. We refer to this experiment as the control experiment.

\section{Sensitivity experiment and ensemble members}

To investigate the influence of TC Mora on the frontal rainfall over Northern Taiwan, we conducted sensitivity experiments. Using the potential vorticity inversion technique ${ }^{22}$ used in a previous study, ${ }^{23} \mathrm{TC}$ Mora was removed from the initial data used in the control experiment. After the removal of TC Mora, all physical variables (i.e., horizontal and vertical winds, temperature, geopotential height, and humidity) were modified to achieve dynamic balance in the initial data (Supplementary Fig. 1). To quantify the model uncertainty, we conducted the sensitivity experiment with 11 ensemble members initialized with $99.9-100.1 \%$ (with $0.02 \%$ increment) of the TC Mora vortex removed. We also conducted 11 simulations in the control experiment initialized with $99.9-100.1 \%$ of the TC Mora. However, we presented only one member's result $(100 \%$ removal and retention) in the analysis discussion for both experiments because the results of all ensemble members were quantitatively similar (see Supplementary Figs 3 and 4).

\section{Observational data}

We used the brightness temperature retrieved from the Himawari-8 satellite data ${ }^{24}$ and the Global Satellite Mapping of Precipitation standard product (GSMaP_MVK). Furthermore, we used the Japanese 55-year reanalysis (JRA-55) ${ }^{25,26}$ provided by the Japan Meteorological Agency. The JRA-55 used in this study was a 6-hourly $1.25^{\circ}$ latitude-longitude gridded data set. We used these observational data to show a synopsis of the frontal rainfall and to validate the result of the control experiment.

Frontogenetical function budget analysis

We conducted frontogenetical function budget analysis ${ }^{27}$ to study the development of the frontal system near Taiwan. The budget equation for frontogenetical function is expressed as follows:

$F_{\mathrm{G}}=F_{\text {div }}+F_{\text {def }}+F_{\text {tilt }}+F_{\text {diab }}$,

where $F_{\mathrm{G}}$ is the frontogenetical function, $F_{\mathrm{div}}$ is the divergence term, $F_{\mathrm{def}}$ is the deformation term, $F_{\text {tilt }}$ is the tilting term, and $F_{\text {diab }}$ is the diabatic term.
The terms are expressed in pressure coordinates as follows:

$$
\begin{aligned}
& F_{\mathrm{G}}=\frac{d}{d t}\left|\nabla_{\mathrm{h}} \theta_{e}\right|, \\
& F_{\text {div }}=-\frac{1}{2}\left|\nabla_{\mathrm{h}} \theta_{e}\right| \delta, \\
& F_{\text {def }}=-\frac{1}{\left|\nabla_{\mathrm{h}} \theta_{e}\right|}\left[\frac{1}{2}\left\{\left(\frac{\partial \theta_{e}}{\partial x}\right)^{2}-\left(\frac{\partial \theta_{e}}{\partial y}\right)^{2}\right\} D_{1}+\frac{\partial \theta_{e}}{\partial x} \frac{\partial \theta_{e}}{\partial y} D_{2}\right], \\
& F_{\text {tilt }}=-\frac{1}{\left|\nabla_{\mathrm{h}} \theta_{e}\right|} \frac{\partial \theta_{e}}{\partial p} \nabla_{h} \theta_{e} \cdot \nabla_{h} \omega, \\
& F_{\text {diab }}=\frac{1}{\left|\nabla_{\mathrm{h}} \theta_{e}\right|} \nabla_{h} \theta_{e} \cdot \nabla_{h}\left(\frac{d \theta_{e}}{d t}\right),
\end{aligned}
$$

where $\theta_{e}$ is the equivalent potential temperature, $\nabla_{h}$ is the horizontal differential operator, $d / d t=\partial / \partial t+u \partial / \partial x+v \partial / \partial y+\omega \partial / \partial p$ is the total derivative, $u$ is the zonal wind, $v$ is the meridional wind, and $\omega$ is the pressure velocity; $\delta \equiv \partial u / \partial x+\partial v / \partial y$ is the divergence, $D_{1} \equiv \partial u / \partial x-\partial v / \partial y$ is the stretching deformation, and $D_{2} \equiv \partial v / \partial x+\partial u / \partial y$ is the shearing deformation. In this study, we applied the preceding budget calculation to demonstrate that TC Mora enhanced the divergence and deformation terms and thus considerably contributed to the formation of the front near Northern Taiwan.

\section{DATA AVAILABILITY}

Himawari-8 satellite data are available at http://www.cr.chiba-u.jp, the GSMaP_MVK are available at https://sharaku.eorc.jaxa.jp/GSMaP/index.htm, and the JRA-55 are available at https://jra.kishou.go.jp/JRA-55/index_en.html. The model data used in this study are available from the corresponding author or first author on request.

\section{CODE AVAILABILITY}

The fvGFS code can be downloaded at https://vlab.ncep.noaa.gov/web/fv3gfs. All analysis codes used in this study are available from the corresponding author or first author on request.

\section{ACKNOWLEDGEMENTS}

The authors thank Prof. Yi-Leng Chen of the University of Hawai'i at Mānoa for his helpful discussion, Dr Yi-Chao Wu of the National Science and Technology Center for Disaster Reduction in Taiwan for providing the historical heavy rainfall information, and Prof. Shu-Chih Yang of National Central University for the discussion about the forecast skill of the heavy-rainfall event. The authors are also grateful to two anonymous reviewers for their constructive comments and encouragements. This study was supported by the Ministry of Science and Technology of Taiwan through a grant (MOST 107-2119-M-001-010-) and the CWB Grant 1072249B. The CWB provided computing facility for numerical experiments. Himawari-8 satellite data were provided by the Center for Environmental Remote Sensing, Chiba University, the GSMaP_MVK was produced and distributed by the Earth Observation Research Center, Japan Aerospace Exploration Agency, and the JRA-55 data sets are provided by the Japan Meteorological Agency.

\section{AUTHOR CONTRIBUTIONS}

H.-H.H. designed the research and helped revise the paper. S.A. performed analysis, drew all figures, and wrote the initial draft and the revised paper. C.-Y.T. and S.-J.L. provided the numerical model. Z.-Y.Y. performed the numerical experiments. H.-C.L. handled the model output.

\section{ADDITIONAL INFORMATION}

Supplementary Information accompanies the paper on the npj Climate and Atmospheric Science website (https://doi.org/10.1038/s41612-019-0082-8).

Competing interests: The authors declare no competing interests.

Publisher's note: Springer Nature remains neutral with regard to jurisdictional claims in published maps and institutional affiliations. 


\section{REFERENCES}

1. Chen, C.-S. \& Chen, Y.-L. The rainfall characteristics of Taiwan. Mon. Weather Rev. 131, 1323-1341 (2003).

2. Chen, G. T.-J., Wang, C.-C. \& Lin, L.-F. A diagnostic study of a retreating Mei-Yu front and the accompanying low-level jet formation and intensification. Mon. Weather Rev. 134, 874-896 (2006).

3. Wang, C.-C., Chen, G. T.-J. \& Ho, K.-H. A diagnostic case study of Mei-Yu frontal retreat and associated low development near Taiwan. Mon. Weather Rev. 144, 2327-2349 (2016).

4. Chen, G. T.-J. \& Chang, C.-P. The structure and vorticity budget of an early summer monsoon trough (Mei-Yu) over southeastern China and Japan. Mon. Weather Rev. 108, 942-953 (1980).

5. Chen, G. T.-J. \& Yu, C.-C. Study of low-level jet and extremely heavy rainfall over Northern Taiwan in the Mei-Yu season. Mon. Weather Rev. 116, 884-891 (1988).

6. Chen, G. T.-J. Mesoscale features observed in the Taiwan Mei-Yu season. J. Meteorol. Soc. Jpn. 70, 497-516 (1992).

7. Chen, G. T.-J. Characteristics of low-level jets over Northern Taiwan in Mei-Yu season and their relationship to heavy rain events. Mon. Weather Rev. 133, 20-43 (2005).

8. Tu, C.-C., Chen, Y.-L., Lin, P.-L. \& Du, Y. Characteristics of the marine boundary layer jet over the South China Sea during the early summer rainy season of Taiwan. Mon. Weather Rev. 147, 457-475 (2019).

9. Gong, C.-Y. et al. The rank of extreme rainfall events over Taiwan (National Science and Technology Center for Disaster Reduction, Taipei, Taiwan, 2015). https:// watch.ncdr.nat.gov.tw/watch_ebook.aspx.

10. Yeh, H.-C., Chen, G. T.-J. \& Liu, W. T. Kinematic characteristics of a Mei-Yu front detected by the QuikSCAT oceanic winds. Mon. Weather Rev. 130, 700-711 (2002).

11. Takaya, K. \& Nakamura, H. A formulation of a phase-independent wave-activity flux for stationary and migratory quasigeostrophic eddies on a zonally varying basic flow. J. Atmos. Sci. 58, 608-627 (2001).

12. Galarneau, T. J. Jr., Bosart, L. F. \& Schumacher, R. S. Predecessor rain events ahead of tropical cyclones. Mon. Weather Rev. 138, 3272-3297 (2010).

13. Lin, S.-J. \& Rood, R. B. An explicit flux-form semi-Lagrangian shallow-water model on the sphere. Q. J. R. Meteorol. Soc. 123, 2477-2498 (1997).

14. Lin, S.-J. A finite-volume integration method for computing pressure gradient force in general vertical coordinates. Q. J. R. Meteorol. Soc. 123, 1749-1762 (1997).

15. Lin, S.-J. A "vertically Lagrangian" finite-volume dynamical core for global models. Mon. Weather Rev. 132, 2293-2307 (2004).

16. Hazelton, A. T., Harris, L. \& Lin, S.-J. Evaluation of tropical cyclone structure forecasts in a high-resolution version of the multiscale GFDL fVGFS model. Weather Forecast. 33, 419-442 (2018).
17. lacono, M. J. et al. Radiative forcing by long-lived greenhouse gases: calculations with the AER radiative transfer models. J. Geophys. Res. 113, D13103 (2008).

18. Arakawa, A. \& Schubert, W. H. Interaction of a cumulus cloud ensemble with the large-scale environment, Part I. J. Atmos. Sci. 31, 674-701 (1974).

19. Han, J. \& Pan, H.-L. Revision of convection and vertical diffusion schemes in the NCEP Global Forecast System. Weather Forecast. 26, 520-533 (2011).

20. Lin, Y.-L., Farley, R. D. \& Orville, H. D. Bulk parameterization of the snow field in a cloud model. J. Clim. Appl. Meteorol. 22, 1065-1092 (1983).

21. Chen, J.-H. \& Lin, S.-J. Seasonal predictions of tropical cyclones using a $25-\mathrm{km}-$ resolution general circulation model. J. Clim. 26, 380-398 (2013).

22. Davis, C. A. \& Emanuel, K. A. Potential vorticity diagnosis of cyclogenesis. Mon. Weather. Rev. 119, 1929-1953 (1991).

23. Hirota, N., Takayabu, Y. N., Kato, M. \& Arakane, S. Roles of an atmospheric river and a cutoff low in the extreme precipitation event in Hiroshima on 19 August 2014. Mon. Weather Rev. 144, 1145-1160 (2016).

24. Bessho, K. et al. An introduction to Himawari8/9-Japan's new-generation geostationary meteorological satellites. J. Meteorol. Soc. Jpn. 94, 151-183 (2016).

25. Kobayashi, S. et al. The JRA-55 reanalysis: General specifications and basic characteristics. J. Meteorol. Soc. Jpn. 93, 5-48 (2015).

26. Harada, Y. et al. The JRA-55 reanalysis: representation of atmospheric circulation and climate variability. J. Meteorol. Soc. Jpn. 94, 269-302 (2016).

27. Ogura, Y. \& Portis, D. Structure of the cold front observed in SESAME-AVE III and its comparison with the Hoskins-Bretherton frontogenesis model. J. Atmos. Sci. 39, 2773-2792 (1982).

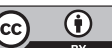

Open Access This article is licensed under a Creative Commons Attribution 4.0 International License, which permits use, sharing, adaptation, distribution and reproduction in any medium or format, as long as you give appropriate credit to the original author(s) and the source, provide a link to the Creative Commons license, and indicate if changes were made. The images or other third party material in this article are included in the article's Creative Commons license, unless indicated otherwise in a credit line to the material. If material is not included in the article's Creative Commons license and your intended use is not permitted by statutory regulation or exceeds the permitted use, you will need to obtain permission directly from the copyright holder. To view a copy of this license, visit http://creativecommons. org/licenses/by/4.0/.

(c) The Author(s) 2019 